\title{
Monterrey. Correo literario de Alfonso Reyes: a publicação do escritor-embaixador e suas convergências e dissonâncias em relação às diretrizes oficiais da Secretaria de Relações Exteriores do México (1930-1937) ${ }^{1}$
}

\author{
Monterrey. Correo literario de Alfonso Reyes: the publication of the \\ writer-ambassador and his convergences and dissonances towards \\ the official guidelines of the department offoreign affairs of Mexico \\ (1930-1937)
}

\section{Natally Vieira Dias ${ }^{2}$}

\section{RESUMO}

O artigo analisa os interesses políticos envolvidos na publicação do periódico Monterrey. Correo Literario de Alfonso Reyes, entre 1930 e 1937, em sua maior parte durante o período em que o escritor mexicano atuava como embaixador de seu país no Brasil. A proposta é ampliar a visão que normalmente tem sido apresentada do periódico, simplesmente como um projeto pessoal do escritor com fins literários. O argumento desenvolvido é o de que a publicação de Monterrey também comportou uma função política que se inseria em um projeto maior, de cunho oficial, de promoção internacional do México pósrevolucionário. A análise do periódico permite identificar a participação ativa do escritor-embaixador Alfonso Reyes nessa política diplomática, mas também alguns elementos de dissonância entre a sua atuação e as diretrizes oficiais da política externa mexicana no período.

Palavras-chave: México pós-revolucionário. Diplomacia cultural. Monterrey. Alfonso Reyes.

\section{ABSTRACT}

The current article analyses the political interests involved in the publication of the periodical Monterrey. Correo Literario de Alfonso Reyes, between 1930 and 1937, mostly during the period in which the Mexican writer acted as ambassador of his country in Brazil. The proposal is to expand the vision that has been

\footnotetext{
1 - Pesquisa com financiamento parcial da CAPES, cujos resultados são apresentados neste artigo ${ }^{2}$ Doutora em História(UFMG). Professora Adjunta da Universidade Estadual de Maringá (UEM). e-mail: natyvdias@gmail.com
} 
shown of this periodical, simply as a personal project of the writer with literary purposes. My argument is that the Monterrey has also had a political function which was part of an official project geared towards international promotion of the post-revolutionary Mexico. By analysing this periodical, I can identify the active participation of the writer-ambassador Alfonso Reyes in this diplomatic policy and we can also identify some dissonant elements between his actuation and the official guidelines of the Mexican external politic in the period.

Keyword: Post-revolutionary Mexico. Cultural diplomacy. Monterrey. Alfonso Reyes..

\section{Introdução}

A figura intelectual de Alfonso Reyes (1889-1959) praticamente dispensa apresentações no cenário latino-americano. Considerado o mais importante escritor mexicano da primeira metade do século XX (CASTAÑóN, 2005), ${ }^{3}$ Reyes foi também uma estrela de primeira grandeza no contexto continental, dentro do qual pode ser identificado como parte da "elite intelectual", no sentido atribuído por Carlos Altamirano (2008) ao termo, que visa "indicar um lugar [privilegiado] no diferenciado espaço da cultura."4 Advogado de formação, Reyes foi poeta e ensaísta e atuou durante boa parte de sua vida como diplomata, tendo representado internacionalmente o México por mais de duas décadas, sendo a embaixada brasileira (19301936) a mais longa de sua carreira diplomática. ${ }^{5}$

Dentro da atuação desse importante personagem intelectual do continente, o periódico Monterrey. Correo literario de Alfonso Reyes ocupa um lugar de destaque. Em trabalhos recentes sobre a configuração de uma rede intelectual articulada em torno da figura de Reyes, o historiador colombiano-mexicano Aimer Granados (2012a) vem destacando a centralidade desse "correio literário" como sendo o "ápice na comunicação desta rede", constituída pelo escritor mexicano "a partir de sua posição como diplomata." Como afirma Granados (2012a), "Reyes empregou a diplomacia como um mecanismo através do qual impulsionou a conformação de uma rede de escritores com caráter transnacional latino-americano e transatlântico vis a vis América-Europa", formada por uma pequena "elite vinculada ao mundo das letras e da cultura." (GRANADOS, 2012a, p. 21-22) Assim, ente os anos 20 e 30, a partir dos contatos intelectuais estabelecidos em várias partes do mundo, mas sobretudo no continente americano, Reyes conseguiu "configurar e estabelecer uma rede intelectual que,

\footnotetext{
${ }^{3}$ Uma boa coletânea de estudos sobre diversas facetas literárias e intelectuais de Alfonso Reyes pode ser encontrada em Díaz Arciniega (1990).

${ }^{4} \mathrm{~A}$ tradução de todos os textos em língua estrangeira é de nossa autoria.

${ }^{5}$ Alfonso Reyes também foi representante diplomático do México na Espanha, de 1920 a 1924; na França, entre 1925 a 1927; e na Argentina, de 1927 a 1930.
} 
por sua vez, foi muito importante em termos da redefinição do campo intelectual e literário da América Latina." (GRANADOS, 2012b, p. 95, 98)

Por toda essa dimensão ocupada na trajetória intelectual de Reyes, o seu Monterrey tem sido tema de vários trabalhos acadêmicos, tanto de historiadores quanto de estudiosos da literatura, sendo os já citados trabalhos de Aimer Granados alguns dos principais exemplos desses estudos. Nesses trabalhos, Granados enfatiza o caráter cultural do "correio literário", que teria funcionado como uma espécie de "carta circular aos amigos", o que "permitiu a Reyes construir para si próprio um espaço que lhe possibilitou certo retiro parcial do mundo da diplomacia e da política." (GRANADOS, 2012a, p. 22) Nessa mesma direção, cujo enfoque é o caráter pessoal do empreendimento cultural de Alfonso Reyes, a crítica literária brasileira Lívia Reis - atualmente uma das grandes estudiosas brasileiras de Monterrey no campo dos estudos literários - também coloca em destaque o caráter "personalíssimo" da publicação, caracterizando-a como um periódico “em primeira pessoa." (REIS, 2007, p. 121).

A proposta do presente artigo é matizar um pouco o caráter pessoal de Monterrey e questionar o aspecto exclusivamente cultural que é atribuído a esse periódico. Mostraremos que o "correo literario de Alfonso Reyes" também cumpriu um significativo papel dentro da estratégia de uma política continental de cunho anti-imperialista e anti pan-americanista empunhada pelo México a partir da Revolução Mexicana.

Nossa análise perpassa, portanto, a temática das relações internacionais e do papel dos intelectuais nesse âmbito. Articulamos ambas as questões a partir dos pressupostos teóricometodológicos da chamada Nova História Política (REMOND, 2003). Dentro dessa perspectiva teórica, compartilhamos da posição de alguns historiadores das relações internacionais (DUROSELLE, 1998; MILZA, 2003) que defendem a existência de articulações intrínsecas entre política interna e política externa, mas geralmente com a predominância da primeira sobre a segunda. Acreditamos que essa compreensão se expressa de maneira exemplar no do México pós-revolucionário. Como tem sido mostrado por parte da recente historiografia mexicana, a política continental empreendida pelos governos mexicanos para firmar o país internacionalmente foi um processo não apenas simultâneo, mas complementar ao movimento interno de busca da coesão nacional em torno de uma identidade comum após a Revolução Mexicana. ${ }^{6}$ Esses trabalhos historiográficos também apontam para a centralidade que foi atribuída à cultura e, no plano externo, à diplomacia cultural como uma ferramenta para consolidar a legitimidade do novo Estado mexicano.

Mostraremos como a publicação de Monterrey se articulou dentro dessa estratégia diplomática oficial, que foi conscientemente apoiada por Alfonso Reyes enquanto representante diplomático de seu país. Nesse sentido, desenvolvemos o argumento de que o periódico Monterrey de Alfonso Reyes funcionou como um espaço de projeção internacional

\footnotetext{
${ }^{6}$ Consultar a respeito: La Cueva e Palacios (2009); La Cueva (2003, 2010).
} 
do México pós-revolucionário, mas comportou tanto elementos de alinhamento quanto de dissonância em relação aos ditames oficiais da Secretaria mexicana de Relações Exteriores no período abordado.

\section{Monterrey. Correo literario de Alfonso Reyes muito além do personalismo}

O "correio literário" começou a ser publicado pelo escritor mexicano em 1930, logo após sua chegada ao Rio de Janeiro como embaixador de seu país. A publicação perpassou todo o período diplomático de Reyes no Brasil (1930-1936), deixando de ser editado apenas em 1937, quando ele já encontrava-se na Argentina.

Durante o período em que foi editado, esse "correio literário" - como Alfonso Reyes o caracterizou - não teve uma periodicidade definida, sendo que a distância temporal entre cada uma de suas edições oscilou de cerca de dois meses a mais de um ano. Seu aspecto material lembrava o de um tabloide, sendo menor do que o formato típico de um jornal diário; cada edição possuía uma média de 8 páginas. ${ }^{7}$

O escritor-embaixador mexicano era o diretor e editor do periódico, além de praticamente o único a publicar textos no mesmo, sendo que outras colaborações somente eram realizadas mediante seu convite. Monterrey era publicado sempre em espanhol (com exceção de uma colaboração do poeta brasileiro Ronald de Carvalho, publicada em português na edição $\mathrm{n}^{\circ}$ 5, de julho de 1931), ${ }^{8}$ embora 13 dos seus 14 números tenham sido editados no Brasil.

$\mathrm{O}$ aspecto personalista desse empreendimento cultural é quase sempre enfatizado exatamente pelo fato de o escritor-embaixador ter sido o único editor e praticamente também o único autor da publicação, que só contou com colaborações solicitadas diretamente por Reyes - casos, por exemplo, de Pedro Henríquez-Ureña e Ronald de Carvalho. Além disso, o periódico era obsequiado por seu próprio idealizador e editor a seus "amigos", como costumava se referir aos colegas com os quais mantinha contato intelectual. Cada edição do

\footnotetext{
${ }^{7}$ Existe uma edição fac-similar do periódico e a ela nos remetemos em todas as citações referentes ao mesmo neste artigo (PACHECO et al., 2008).

${ }^{8}$ Tratou-se de uma reflexão do poeta brasileiro sobre as complexidades envolvidas nos processos de tradução entre espanhol e português, que foi realizada a partir de sua própria tentativa de traduzir um poema do escritor mexicano Amado Nervo. (CARVALHO, 1931).
} 
"correio literário" era composta por cerca de 300 exemplares, que não eram vendidos, mas distribuídos gratuitamente pelo próprio diretor/editor a seus "amigos" intelectuais.

Apesar do número de exemplares parecer grande para esse tipo de distribuição, que o próprio Reyes qualificou de "praticamente uma carta circular" entre amigos (REYES, Monterrey, $\mathrm{n}^{\circ}$ 1, 1930, p. 2), não é difícil compreender a extensa dimensão dos "amigos" intelectuais do escritor-embaixador mexicano quando observamos as inúmeras pastas que abrigam as cartas trocadas por ele com centenas de personagens do cenário cultural mundial e que atualmente compõem o acervo de suas correspondências. ${ }^{9}$ Uma boa dimensão da circulação efetivamente mundial do "correio literário" de Alfonso Reyes pode ser apreendida pela informação, que nos é apresentada pelo historiador mexicano Víctor Díaz Arciniega (2001, p. 48), de que a distribuição de Monterrey chegou "até lugares tão distantes como Madagascar."

Ainda a respeito do caráter personalista do periódico, o próprio nome da publicação indicava que se tratava de uma produção cultural do escritor, já que o título Monterrey fazia referência à cidade natal do escritor-embaixador mexicano; o subtítulo se referia a um correo literario de Alfonso Reyes; e até mesmo o emblema do periódico - o cerro de Monterrey, desenhado de próprio punho por Reyes e assinado com suas iniciais - fazia referência às montanhas da região onde ele havia nascido (imagens 1 e 2).

Ao lermos o correo literario de Alfonso Reyes podemos perceber claramente que foi ele próprio o primeiro a tentar submeter Monterrey a toda uma aura de personalismo e erudição que, em grande medida, continua guiando os estudos a respeito do periódico. Já no primeiro número da publicação, no editorial de apresentação intitulado "Propósito", Reyes expressou a seus "amigos" leitores qual seria intenção da nova publicação:

[Este será] um jornal literário de um só autor. [...] Modestamente disposto a ser um campo de pesquisas literárias [...]; [e] prestando-se ao diálogo entre os amigos que queiram [...] trocar erudições por este meio; sempre hospitaleiro, mas sempre casa privada e não edifício público, sempre morada de uma só pessoa. [...] [Será] um impresso de obséquio, uma carta impressa (REYES, Monterrey, $\mathrm{n}^{\circ}$ 1, 1930, p. 2. Grifo nosso.)

${ }^{9}$ Esse acervo encontra-se sediado e organizado na chamada Capilla Alfonsina, antiga casa de Alfonso Reyes na Cidade do México, que atualmente comporta a maior parte de seus arquivos pessoais. 


\section{Imagem 1}

Primeira página da edição inicial de Monterrey

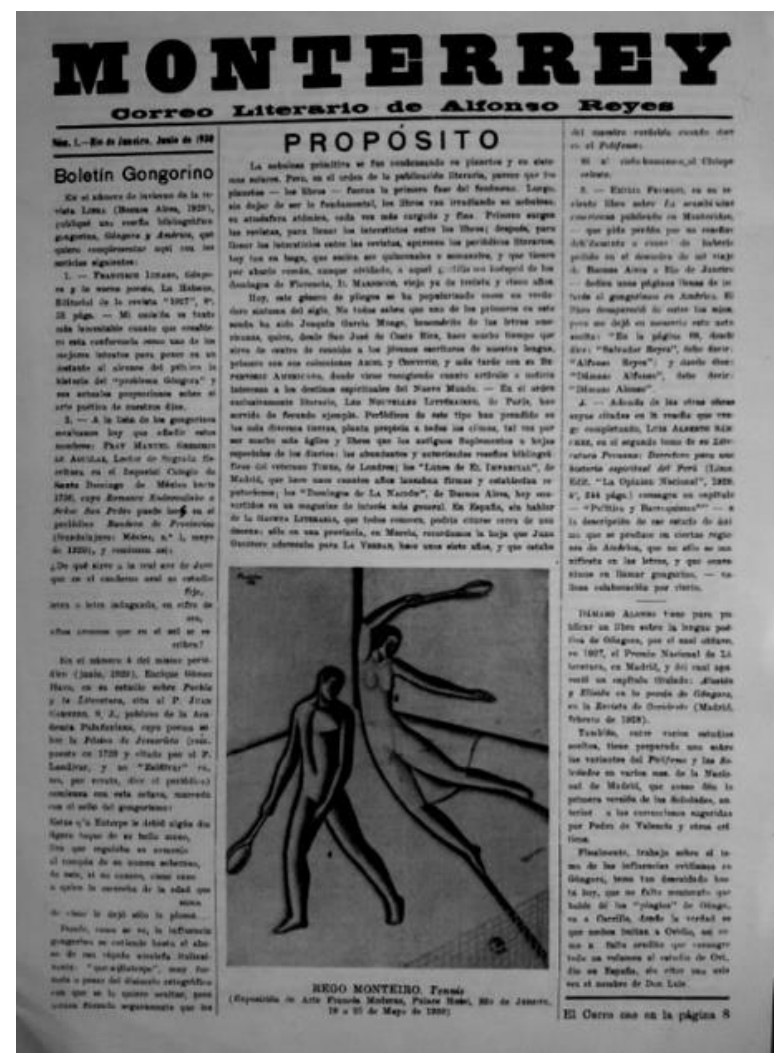

Fonte: Monterrey. Correo literario de Alfonso Reyes, $1^{\circ}$ de junho de 1930

\section{Imagem 2}

Emblema de Monterrey, reproduzido em todas as edições da publicação

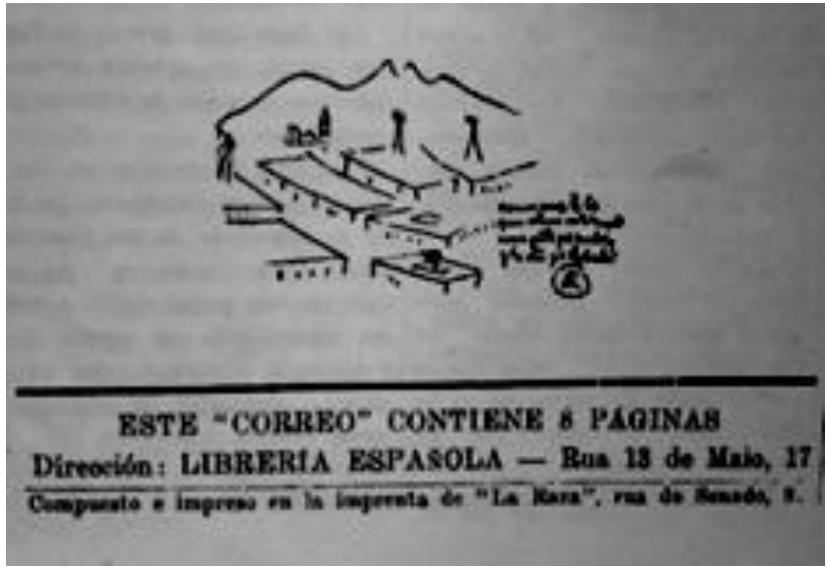

Fonte: Monterrey. Correo literario de Alfonso Reyes 
Erudição e personalismo apresentavam-se, dessa maneira, plasmados já no editorial de fundação do "correio literário". Sem dúvida, esses dois aspectos são de extrema relevância e fornecem como que os contornos gerais do periódico. À primeira vista, Monterrey não parece ser mais do que um simples espaço de "troca de erudições", exatamente um "correio literário" cujos principais temas eram os clássicos da Literatura e iam da Antiguidade latina - com destaque para o poeta Virgilio - ao romantismo europeu - principalmente a obra de Goethe -, passando pelo melhor do "século de ouro" espanhol, incluindo grandes autores da Nova Espanha. Para se ter uma noção desse caráter erudito, basta mencionar a existência de uma seção fixa do periódico, intitulada "Boletín", na qual Reyes publicava seus próprios estudos e também dava notícia de outros realizados, tanto por espanhóis quanto por latino-americanos, sobre o escritor novo-hispano Juan Ruiz de Alarcón e o espanhol Luis de Góngora, sendo que este último chegou a ganhar um espaço específico na publicação, o "Boletín Gongorino".

Dessa forma, ao se folhear os quatorze números do correio literario de Alfonso Reyes podese ficar com a impressão de que este servia unicamente como um canal de diálogo literário, uma publicação que era, de fato, editada, dirigida e distribuída gratuitamente por seu próprio idealizador a quem lhe aprazia. Mas Monterrey também pode nos revelar uma outra faceta, bem menos pessoal, dentro da qual a própria erudição ficava em segundo plano em face de uma ação mais pragmática, cujo foco era zelar pela imagem internacional do México. Não podemos perder de vista que o idealizador e produtor do periódico era, além de escritor, um representante oficial de seu país no exterior, papel que denota em si mesmo uma intensa relação entre o intelectual Alfonso Reyes e a política oficial mexicana.

\section{Alfonso Reyes, a política e a diplomacia}

Parte da dificuldade que tanto da historiografia quanto os estudos literários têm demonstrado para vislumbrar o elemento político latente no "correio literário" de Reyes se relaciona com a pouca importância que normalmente é conferida à faceta política do próprio Alfonso Reyes; na maior parte das vezes essa dimensão é deixada de lado e praticamente ofuscada pela imagem do erudito homem de letras.

Em um estudo recente, que resgata a dimensão política da atuação do escritorembaixador mexicano a partir da leitura de seus relatórios diplomáticos, precisamente durante o período no Brasil, o historiador Alberto Enríquez Perea comenta que a imagem convencional de Reyes através da qual "a historiografia mexicana e estrangeira nos acostumou [a vê-lo]" - fundamentalmente como um "homem distante da política, fechado em sua concha de caracol, lendo e relendo seus clássicos espanhóis e greco-latinos" -, dificultou 
durante muito tempo percebê-lo não apenas como "um homem apaixonado pela política" mas, principalmente, como alguém "comprometido politicamente". (ENRÍQUEZ PEREA, 2009, p. 5, 520) Exatamente o compromisso político de Reyes com o Estado mexicano foi apontado por Javier Garciadiego (1998) como um dos fatores essenciais para o seu "êxito" como diplomata. Conforme destaca, Reyes não apenas foi "ideologicamente afim" aos governos do México pós-revolucionário, como manteve uma postura de "leal[dade] às autoridades e às instituições governamentais", o que inclusive chegou a "lhe custar o distanciamento [...] e numerosas recriminações por parte de outros intelectuais." (GARCIADIEGO, 1998, p. 206, 210)

Esse comprometimento, devemos ressaltar, não significou a ausência de críticas por parte de Reyes aos direcionamentos oficiais de seu país, o que ocorreu especialmente no terreno cultural, como veremos mais à frente. Mas, para compreender sua atuação enquanto diplomata e o papel político cumprido por Monterrey, é essencial não perder de vista o comprometimento do escritor-embaixador com as políticas oficiais mexicanas e muito particularmente com a política externa de propaganda do México pós-revolucionário, que, aliás, ganhou contornos bastante sofisticados em sua própria atuação como embaixador. Se essa função, por si própria, já pressupunha a ideia mais geral de uma representação (diplomática), Reyes a preencheu com atributos bastante específicos e personalizados que evocam propriamente a noção do embaixador como uma "personificação" de seu país.

Alfonso Reyes chegou a esboçar reflexões teóricas em torno da função de representação diplomática em um texto intitulado El servicio diplomático mexicano, escrito, em 1933, como uma resposta ao governo mexicano, que havia solicitado a seus diplomatas que fizessem sugestões para melhorar a representação externa do país. No referido texto, explicou que, em sua concepção, a função diplomática podia ser resumida na ideia de "ganhar amigos", o "sábio conselho" dado, já no século XVII, pelo escritor novo-hispano Juan Ruíz de Alarcón. Isso significava ampliar "a captação de boas vontades" para com o país, algo que se podia conquistar, de forma bem mais efetiva, por meio de contatos pessoais e intelectuais, que ganhavam, assim, um sentido estratégico. Para Reyes, uma diplomacia eficiente se produzia a partir de contatos personalizados e a representação externa do país era "uma função que se funda[va] na personalidade individual, irredutível, intransmissível" do diplomata. Este, conforme entendia o escritor-embaixador mexicano, era "uma pessoa, mais que uma atividade"; "um substantivo, mais que um verbo: um ser, mais que um fazer". Do seu ponto de vista, o representante diplomático seria um mediador, "tradutor ou conciliador entre o seu próprio país e o outro", no qual o representava; por isso considerava que a própria pessoa do diplomata contava de maneira decisiva, já que, muitas vezes, "sua simples presença, seu trato [com os outros], suas relações pessoais [...] seriam determinantes.” (REYES, 2001, p. 152-153, 161, grifo nosso) 
Como se poderia esperar de uma visão tão pessoalizada da diplomacia, havia, na perspectiva de Reyes, um tipo específico de "personalidade individual" capaz de exercer tal função da maneira mais eficaz: os literatos. Estes eram os "técnicos da expressão" e, por isso mesmo, os "mais adequados para 'expressar' a vontade do país no exterior e os mais armados para explicar as coisas da pátria." A metáfora bélica empregada por ele não era, de forma alguma, fortuita ou um simples jogo de palavras, mas expressava a visão absolutamente estratégica, no sentido político do termo, a partir da qual o escritor-embaixador pensava e exercia a diplomacia. Segundo manifestou explicitamente no texto de cunho teórico, de 1933, suas concepções sobre a diplomacia se inspiravam "no critério de que o corpo diplomático é uma ordem técnica" e que esta "tem em comum com o serviço militar o fato de ser um serviço de defesa". Exatamente essa percepção fazia com que o escritor-embaixador visse a si próprio, e aos diplomatas mexicanos em geral, como pessoas que exerciam a função de um "soldado", um "sentinela nacional destacado em terras distantes". Deles dependia, em muitos sentidos, a proteção, "a estabilidade" da pátria em suas "necessidades da vida internacional". (REYES, 2001, p. 132-133, 141, 152-153,165, grifo nosso).

Esse modelo de diplomacia não foi apenas defendido, mas também encarnado pelo próprio Alfonso Reyes enquanto embaixador. E o seu não era um caso isolado; conforme ele mesmo assinalou, "era perceptível por parte do governo mexicano o desejo de aproveitar os escritores no serviço diplomático" e deles se esperava "a propaganda cultural e espiritual" que se "exigia" da "representação" mexicana em outros países. (Idem, p. 142-3) ${ }^{10}$ Essa visão estratégica da cultura como elemento central da política diplomática, marcante nas proposições teóricas de Reyes, encontrava-se bastante alinhada à posição oficial mexicana. De fato, a diplomacia cultural foi "uma característica paradigmática" (LA CUEVA; PALACIOS, 2009, p. 26) da política externa do México pós-revolucionário, um mecanismo empreendido pelos governos mexicanos para firmar internacionalmente uma imagem positiva do novo México, surgido da Revolução de 1910, e combater os estigmas de violência e instabilidade que pairavam sobre a visão que se tinha do país no exterior, em decorrência do violento processo revolucionário.

Como atualmente o conceito de diplomacia cultural tem sido usado para se referir aos mais diversos tipos de relações culturais envolvendo os mais variados atores, sejam grupos, pessoas ou instituições de países diferentes, com objetivos de maior aproximação e conhecimento mútuos - um tipo de ação que pode ser definida muito mais em termos de "relações culturais internacionais" -,11 é necessário enfatizar que, no caso do México pós-

\footnotetext{
${ }^{10}$ Entre os escritores mexicanos que atuavam como diplomatas, na época, destacam-se Jaime Torres Bodet, Gilberto Owen e José Rubén Romero, entre vários outros. Ver a respeito: Carballo et al. (1998).

${ }^{11}$ Para o caso específico do México pós-revolucionário, uma concepção mais ampliada de diplomacia cultural foi a utilizada na coletânea organizada por Alicia Azuela de La Cueva e Guillermo Palacios a respeito das relações culturais com os Estados Unidos. Segundo os autores, a diplomacia cultural, entendida não apenas como uma política oficial, mas englobando os mais diversos tipos de "participação consciente de grupos de poder [...] no impulso das relações culturais [entre países]", foi uma "ferramenta" essencial para "suavizar ou mediar conflitos" entre os dois países nas décadas que se seguiram à Revolução de 1910. (LA CUEVA; PALACIOS, 2009, p. 26.)
} 
revolucionário, o fomento de relações culturais com a América Latina comportou toda uma política diplomática oficial levada a cabo entre meados da década de 1910 e fins dos anos 30 com o objetivo de consolidar internacionalmente a presença do novo Estado surgido da Revolução. Nesse sentido, a atuação mexicana analisada neste artigo se aproxima de um conceito mais específico de diplomacia cultural, empregado para indicar uma particular utilização das relações culturais "para a consecução de objetivos nacionais de natureza não somente cultural, mas também política, comercial ou econômica"; tratando-se, neste caso, de políticas oficiais, de cunho estatal (RIBEIRO, 2011, p. 33, grifo do autor).

A estratégia da diplomacia cultural foi a principal faceta esboçada pelo México pósrevolucionário para exercer uma política externa latino-americanista em franco desafio aos ditames pan-americanistas empunhados pelos Estados Unidos a partir da Conferência de Washington, realizada em 1889. Desde então, a potência continental passou a esboçar a defesa de uma aproximação fundamentalmente comercial entre os países do continente sob sua liderança. $O$ discurso pan-americanista gerou muitas desconfianças em parte da intelectualidade continental - ao ser formulado de forma concomitante à atuação expansionista e agressiva dos Estados Unidos na região, expressa na chamada política do Big Stick -, mas também foi apoiado por parte significativa desta mesma intelectualidade, com destaque para o caso do Brasil, cuja política externa historicamente era marcada pelo afastamento de seus vizinhos continentais e pela aproximação em relação à potência continental. ${ }^{12}$

Como bem salienta Pablo Yankelevich $(1997,1999)$, a política latino-americanista exercida pelo México pós-revolucionário deve ser entendida como "um ato defensivo" em relação à política estadunidense que desafiou a legitimidade do processo revolucionário mexicano, inclusive por meio de uma intervenção militar. ${ }^{13}$ Foi em defesa de sua autonomia - e, portanto, contra os princípios intervencionistas estadunidenses - que o México pósrevolucionário passou a impulsionar a identidade latino-americana, encabeçando "propostas de corte 'indo-americano" - no sentido de valorização de uma identidade considerada autóctone, não necessariamente indígena - "em aberto desafio ao pan-americanismo reinante". A base dessa estratégia diplomática, que era concebida como uma "retaguarda internacional" para a Revolução Mexicana, foi construída ainda durante a fase armada da Revolução e guiou a política continental mexicana até os anos 30 (YANKELEVICH, 1997, p. 373, 386)

É dentro dessa ampla e articulada estratégia diplomática que o "correio literário" de Alfonso Reyes pode ser compreendido de forma mais aprofundada em sua dimensão política.

${ }^{12}$ Sobre a ascensão da perspectiva pan-americanista e seu embate com latino-americanismo e sobre o histórico das relações do Brasil com o entorno continental, com ênfase para o posicionamento oficial da diplomacia brasileira e os debates intelectuais a respeito do tema, consultar respectivamente: Ardao (1986); Baggio (1998); Bueno (2003); Prado (2001).

${ }^{13} \mathrm{Em}$ abril de 1914, em meio ao processo revolucionário no México, o governo dos Estados Unidos ordenou o desembarque de seus marines no porto mexicano de Vera Cruz numa tentativa frustrada de acabar com a guerra civil no país vizinho. 


\section{Monterrey como uma vitrine internacional para o México pós-revolucionário}

Na realidade, o que uma leitura atenta de Monterrey nos revela é uma significativa interseção entre o projeto intelectual de Reyes e o grande objetivo da política externa mexicana no período, que era consolidar internacionalmente uma imagem positiva do México pós-revolucionário. Esse sentido político, que pode ser sintetizado na noção de uma "defesa do México", chegou a ser tocado pelo jornalista mexicano Marcos Daniel Aguilar, em um estudo sobre o periódico de Reyes que enfatiza a dimensão política que se pode vislumbrar, segundo o autor, "sutilmente", "nas entrelinhas", em temas como a defesa do país e de sua cultura, bem como da América Latina e sua cultura (AGUILAR, 2013, p. 122).

Mas queremos chamar a atenção para a existência de uma dimensão ainda mais pragmática, politicamente falando, no periódico; um espaço em que a própria temática cultural ficava em segundo plano em relação ao universo especificamente político. Esse é o caso da coluna "Noticia mexicana", que foi publicada nos primeiros nove números de Monterrey, entre 1930 e 1932, e que diferia da maior parte do discurso do periódico por seu tom claramente propagandístico do México revolucionário, num sentido que ia muito além de seus aspectos culturais.

Antes de abordarmos diretamente o conteúdo da referida coluna, convém destacar um elemento central que nos ajuda a perceber as intrínsecas relações político-diplomáticas que perpassaram a edição de Monterrey: o período de publicação da coluna "Noticia Mexicana", que foi também o de maior vigor do próprio periódico, quando este teve uma periodicidade mais estável, coincide parcialmente com a gestão do escritor Genaro Estrada à frente da Secretaria de Relações Exteriores do México, entre 1930 e 1932. Nesse período a chamada "diplomacia das letras" - a designação de literatos para as representações diplomáticas mexicanas - assumiu uma centralidade ainda maior dentro da ampla estratégia de diplomacia cultural que marcou a inserção internacional do México pós-revolucionário. As embaixadas sul-americanas de Alfonso Reyes foram casos exemplares dessa política diplomática.

Tanto na Argentina (entre 1927 e 1930) quanto no Brasil (entre 1930 e 1936), Reyes levou a cabo uma atuação diplomática cujo foco era alcançar uma boa "representação social do México", que funcionasse para além e independentemente dos imprevisíveis sucessos diplomáticos oficiais, conforme destacou em carta ao secretário Genaro Estrada, ao chegar ao Rio, após deixar a Embaixada de Buenos Aires (REYES, 1930 apud ZAÏTZEFF, 1993, p. 32) Com 
base nesse objetivo, Estrada e Reyes - que eram amigos pessoais e cujas "educadas sensibilidades intelectuais e os perceptivos tatos políticos" andavam em sintonia - "tece[ra]m uma compacta rede de relações diplomáticas", que se constituiu "a partir da secretaria, onde Estrada est[ava] atento aos passos de Reyes", enquanto este, nas Embaixadas, "segu[ia] as instruções de Estrada." (DÍAZ ARCINIEGA, 2001, p. 37-38) Há indícios significativos de que a publicação de Monterrey inseriu-se pragmaticamente dentro desse objetivo de cunho políticodiplomático, para além do desejo pessoal do escritor de editar um "correio literário".

Inicialmente o periódico editado por Alfonso Reyes conseguiu manter uma periodicidade de poucos meses, alcançando nove números em apenas dois anos, entre junho de 1930 e julho de 1932. Essa estabilidade inicial da publicação - que ocorreu basicamente durante a gestão de Genaro Estrada na Secretaria de Relações Exteriores - contrasta fortemente com o período posterior, quando foram editados apenas seis números num período de cinco anos. Somente esses indícios permitiriam questionar, pelo menos em parte, a ideia de que o periódico de Reyes tenha sido tão personalíssimo. Outros indícios que sugerem um apoio oficial do secretário Estrada à iniciativa do escritor-embaixador encontram-se nas correspondências trocadas entre ambos, nas quais Genaro Estrada, além de incentivar a continuidade da publicação, colocou-se à disposição do embaixador para resolver inclusive problemas técnicos em prol da mesma, tais como a aquisição de tipos específicos para a edição em espanhol (a letra ñ e os sinais invertidos de interrogação e exclamação) que não existiam nas prensas brasileiras (ESTRADA, 1931 apud ZAÏTZEFF, 1993, p. 130).

Em diversas cartas enviadas por Reyes a Estrada entre janeiro e junho de 1931 também é possível perceber o empenho do escritor-embaixador em apresentar justificativas sobre a periodicidade de Monterrey, reiterando seu total empenho em soltar o maior número possível de edições do periódico. ${ }^{14}$ Não há a menor dúvida de que o "correio literário" de Reyes funcionou como um instrumento de divulgação de uma imagem positiva - e até certo ponto oficial - do México revolucionário, o que fica evidente na coluna anteriormente mencionada, “Noticia Mexicana”, que será abordada na sequência.

\section{"Notícia Mexicana" e a propaganda do México em Monterrey}

Essa coluna ocupava cerca de $1 / 3$ do espaço do periódico, que possuía uma média de 8 páginas. Ao longo do período em que foi publicada, "Noticia Mexicana" forneceu um rico panorama a respeito da situação do país, ao qual podemos atribuir um caráter

\footnotetext{
${ }^{14}$ Isso aparece nas cartas de Genaro Estrada a Alfonso Reyes datadas de 29/01; 13/02; 27/02; 13/03 e 29/06/1931 (ZAÏTZEFF, 1993, p. 96, 107, 116, 123, 149).
} 
propagandístico do novo México criado pela Revolução. Presente já no primeiro número de Monterrey, a coluna foi apresentada por Alfonso Reyes como um espaço de "descrição bibliográfica" no qual o editor (o próprio Reyes) desenvolveria breves comentários sobre as publicações mexicanas, os quais, afirmava: "não se tratam [...] de verdadeiras resenhas críticas, mas de simples menções destinadas a chamar a atenção do [leitor] aficionado pelas coisas mexicanas." (Monterrey, $\mathrm{n}^{\circ}$ 1, junho de 1930, p. 4) De fato, não se tratavam de resenhas propriamente ditas, mas todas as publicações que Reyes decidia divulgar na coluna contavam com breves, porém sistemáticos, comentários do escritor-embaixador, dotados sempre do tom elegante que caracterizava sua escrita. Nesse espaço, Reyes apresentava seus comentários não apenas a respeito de novidades culturais de seu país, mas igualmente sobre publicações oficiais e, por vezes, dava notícia de obras públicas realizadas pelo governo do México. Na primeira edição de "Notícia Mexicana" - primeira também de Monterrey -, salta aos olhos a intenção do escritor-embaixador de apresentar a ordem institucional mexicana como estável, democrática e legítima, o que se observa em seu comentário - localizado numa subseção de "Noticia Mexicana" intitulada "Historia política" - sobre a obra La rebelión militar contra el gobierno legítimo del señor Presidente de la República, Lic. D. Emilio Portes Gil, descrita e comentada por um observador, publicada em San Antonio, Texas, em 1929. Segundo Reyes, "esse relato deve[ria] ser lido à luz da autorizada monografia de Alberto J. Pani, El cambio de regímenes en México y las asonadas militares (síntesis histórica)", pois neste último livro era apresentada "a linha contínua de uma evolução democrática [mexicana], em meio aos obstáculos que têm sido criados pelas sublevações militares, todas fracassadas desde 1920, ano em que começa a reconstrução." Ainda segundo o comentário de Reyes em Monterrey, as sublevações violentas no México após 1920 não representavam mais que "a depuração ou purga palaciana de um regime político já definido." (Monterrey, $\mathrm{n}^{\circ} 1$, junho de 1930, p. 5)

Esse comentário reproduzia o discurso oficial que identificava no governo de Álvaro Obregón (1920-1924) o início da reconstrução do país, entendida também como estabilização política do regime emanado da Revolução; nesse relato apaziguante e estabilizador, todo e qualquer levantamento armado pós 1920 é deslegitimado como uma luta contra um regime legítimo e democrático "já definido". A importância política desse comentário, por parte de uma voz autorizada como a de Alfonso Reyes, não pode ser minimizada, principalmente num momento em que ainda pairavam no ar a instabilidade política e a violência da Guerra Cristera. ${ }^{15}$ Esse evento comprometeu fortemente a positiva imagem internacional que o México vinha tentando sustentar havia cerca de uma década e inclusive, no caso do Brasil,

\footnotetext{
${ }^{15}$ A chamada Guerra Cristera, ocorrida entre 1926 e 1929, foi um conflito armado que opôs o Estado mexicano aos chamados "soldados de Cristo", liderados pela Igreja Católica. Tratou-se de um dos desdobramentos mais significativos da Revolução Mexicana, sendo que os combates bélicos representaram o culminar de uma crescente hostilidade entre a Igreja Católica e o Estado pós-revolucionário por causa da efetivação dos artigos anticlericais da Constituição de 1917.
} 
acabou gerando uma celeuma diplomática por causa dos ataques dos intelectuais conservadores católicos ao governo mexicano. ${ }^{16}$

Um outro bom exemplo dos inúmeros comentários presentes na coluna "Noticia Mexicana" que contribuíam para a difusão de uma imagem estável e progressista do México pode ser encontrado no quinto número de Monterrey, publicado em meados de 1931, por meio do qual os leitores eram informados de que o governo do México publicava um "Guia explicativo das instituições a serviço dos habitantes do Distrito Federal", no qual dava-se informações sobre diversos órgãos disponíveis à população, como "postos de [...] segurança, asilos, [...] maternidades, [...] reformatórios, [...] consultórios e hospitais, [locais de] vacinação e justiça pública", entre vários outros. Da perspectiva do escritor-embaixador, passada aos leitores de Monterrey, a publicação do referido guia explicativo pelo governo mexicano era uma admirável iniciativa para a divulgação de "conselhos morais, regras de higiene e avisos prudentes". (Monterrey, nº 5, junho de 1931, p. 6)

Citemos ainda outro comentário da coluna que permitia vislumbrar a imagem de um Estado que, não apenas era socialmente progressista, mas também fortemente dedicado à consolidação da infraestrutura nacional. Nas palavras Reyes, "uma das maiores preocupações dos últimos governos mexicanos tem sido o fomento e desenvolvimento das estradas"; "no campo transtornado pela guerra, a estrada chega trazendo novo vigor, segurança e certa comodidade urbana, mesmo nas montanhas mais agrestes." (Monterrey, $\mathrm{n}^{\circ}$ 5, junho de 1931, $\mathrm{p}$. 5)

Como se pode observar pelas citações apresentadas, a leitura de "Notícia Mexicana" permitia ao leitor formar mentalmente uma imagem bastante articulada a respeito do México, descrito como um país progressista, com um Estado organizado e empenhado no atendimento das demandas populares; em suma, uma nação que caminhava no sentido de um amplo desenvolvimento social, que atendia simultaneamente aspectos econômicos e culturais. Estes últimos também foram largamente celebrados na "Noticia Mexicana" de Monterrey. A esse respeito, vale destacar um outro comentário de Reyes, situado na mesma coluna, no qual se pode observar explicitamente o objetivo de difundir uma visão construtiva da revolução de seu país, inclusive no que dizia respeito à dimensão cultural.

\footnotetext{
${ }^{16}$ Durante a Guerra Cristera a revista brasileira $A$ Ordem, dirigida na época por Jackson de Figueiredo, encabeçou uma campanha de ataque às medidas anticlericais do governo mexicano e chegou, inclusive, a levantar fundos para serem enviados aos cristeros mexicanos, que lutavam em favor da Igreja. Mas antes mesmo de chegar às páginas da revista, os ataques de Figueiredo ao governo mexicano já haviam sido expressos em órgãos da grande imprensa e tomado proporções diplomáticas, quando, em resposta aos mesmos, o embaixador mexicano no Brasil na época, Pascual Ortiz Rubio, "ameaçou abandonar o país e levar consigo todo o pessoal da embaixada." Segundo Guillermo Palacios (2008), "o Itamaraty esforçouse por minimizar o incidente in loco e instruiu [Antonio] Feitosa [embaixador brasileiro no México] para que se fizesse saber [no México] que a opinião de Figueiredo de nenhuma forma representava uma postura oficial [brasileira]" (PALACIOS, 2008, p. 231). Sobre a campanha dos católicos brasileiros contra o governo mexicano e em favor dos "soldados de Cristo" do país, consultar: Dias (2015), especificamente o item "Em torno ao conflito religioso no México: os ataques dos conservadores católicos brasileiros" do capítulo 3.
} 
Trata-se de uma referência ao artigo do intelectual socialista Vicente Lombardo Toledano, intitulado "El sentido humanista de la revolución mexicana", publicado no número 5 de Monterrey, em julho de 1931. A leitura do artigo de Lombardo é "recomendada" por Reyes como um "antídoto a muitas declamações vazias" sobre a situação do México, sendo o texto elogiado como "duplamente expressivo, por seu valor intrínseco e por vir da pluma de um representante dos grupos mais avançados de nossa política." Quanto ao "valor intrínseco" do texto, podemos identificá-lo no seguinte comentário do escritor-embaixador, referindo-se ao autor do artigo como alguém que teria sido capaz de perceber o sentido essencial do processo revolucionário:

\footnotetext{
O espetáculo cambiante da vida mexicana durante os últimos vinte anos, mesmo que muitos não consigam ainda percebê-lo claramente, aparecerá na história perpassado por um fio de continuidade cultural, firme e compacto. [...] A vida intelectual [mexicana] não foi interrompida em meio à guerra civil; ao contrário, prosperou visivelmente. E tem mais: os estímulos intelectuais pulsam nas origens de nossa última transformação política [ou seja, a Revolução Mexicana]. (Monterrey, $\mathbf{n}^{\circ} 5$, junho de 1931, p. 6)
}

Como temos ressaltado, é perceptível a intenção propagandística da coluna "Noticia Mexicana" como um todo e essa constatação é reforçada pelo fato de que, nesse espaço do periódico, a função pragmática tendeu a ser priorizada por vezes conscientemente às expensas da excelência cultural/literária, tão característica de Alfonso Reyes. Uma situação em que isso se evidencia ocorreu nos números 6 e 7 de Monterrey (datados de outubro e dezembro de 1931), nos quais Reyes noticiou elogiosamente a publicação, por parte da Secretaria de Educação Pública do México, de uma antologia do escritor modernista Manuel José Othon, organizada pelo poeta Salvador Novo; mas, em privado, numa carta ao secretário Genaro Estrada, apresentou uma duríssima crítica sobre a obra. Na visão de Reyes, tratava-se de "uma edição sem espírito crítico nem respeito pela bibliografia" de Othon; uma antologia que, em sua concepção, não havia sido cuidada mas "descuidada" por Salvador Novo e para a qual caberiam inúmeras críticas. Entretanto, afirmou explicitamente, na referida carta, que tinha se "calado" a respeito disso em Monterrey e "deixado no tinteiro" tudo de ruim que pensava da publicação para não passar uma má imagem do país. Em suas próprias palavras: "como meu fim é apresentar bem o nome do México em Monterrey, apesar de tudo eu me calei." (REYES, 29/10/1931 apud ZAÏTZEFF , 1993, p. 189).

Os casos citados demonstram o uso estratégico empregado por Reyes a seu Monterrey, que inegavelmente funcionou como um órgão de propaganda do México. Tratava-se de uma 
maneira mais sutil de fazer propaganda do país, utilizando-se de um veículo de caráter essencialmente cultural. Não há dúvida quanto à legitimidade ainda maior que poderia ser conferida às "notícias mexicanas" veiculadas pelo periódico do reconhecido escritor Alfonso Reyes, tendo em vista exatamente o fato de aparecerem distanciadas dos estereótipos, muitas vezes grosseiros, das propagandas oficiais.

\section{O latino-americanismo em Monterrey}

Um elemento de central importância na imagem do México projetada através de Monterrey foi a vinculação do país ao tema da solidariedade continental. Essa, como já mencionamos, era a base da política externa mexicana no período e também foi o ideário de fundo do periódico, mesmo porque o engajamento em torno do latino-americanismo era o elemento central que animava a atuação intelectual do próprio Reyes. ${ }^{17}$

Em seu prólogo aos escritos diplomáticos de Reyes, Víctor Díaz Arciniega aponta um elemento importante para o entendimento do engajamento americanista do escritorembaixador nos anos 30, época em que Monterrey foi publicado. O historiador mexicano destaca que o período das embaixadas sul-americanas de Reyes significou a consolidação de uma nova perspectiva do intelectual-diplomata em relação ao tema da integração continental, herdeira da tradição modernista. Diferentemente da concepção daquele movimento essencialmente literário - cujo foco identitário repousava na produção de uma literatura hispano-americana de caráter original -, Reyes passou a conceber a questão da identidade continental dentro de um novo "ciclo", no qual o americanismo ganhava contornos políticos muito mais consistentes (DÍAZ ARCINIEGA, 2001, p. 31-2). Como mostra o historiador mexicano, já em 1914 Reyes argumentava que "os meios fáceis da cor local" simplesmente "não resolv[ia]m esse profundo tema da originalidade" e que "o americanismo, como caráter literário original, seria um dos tantos efeitos de uma causa mais ampla; que não é assunto de poesia nem de prosa, mas problema de política, de educação, de humanidade, de totalidade."18 Díaz Arciniega (2001, p. 35) argumenta que essa mudança na perspectiva americanista de Reyes era consequente com o sentido da política externa mexicana de fomentar o latinoamericanismo como "medida defensiva" contra os interesses estadunidenses.

Conforme já destacamos, essa concepção defensiva da identidade continental foi a base da política externa do México revolucionário até o fim dos anos 30. Mas, já em inícios daquela

\footnotetext{
${ }^{17}$ Sobre a centralidade da perspectiva americanista na atuação intelectual-diplomática de Alfonso Reyes, especialmente durante sua embaixada no Brasil (DIAS, 2013).

${ }^{18}$ Essas reflexões de Alfonso Reyes aparecem em uma carta ao escritor peruano Ventura García Calderón, datada de janeiro de 1914, em resposta a uma pesquisa para a Revista de América, editada em Paris (DÍAZ ARCINIEGA, 2001, p. 32).
} 
década, apesar de manter a postura de não alinhamento aos ditames pan-americanistas, a estratégia de inserção internacional do país se caracterizou por uma posição menos combativa em relação aos Estados Unidos e pela tentativa de ampliar as relações mexicanas para além do espaço continental. ${ }^{19}$ Nesse sentido, conforme observou a historiadora Amelia Kiddle em estudo sobre as relações do México com o entorno latino-americano nos anos 30, a América Latina deixou de ter "a mesma prioridade diplomática que os Estados Unidos e a Europa" para o México naquele momento. Disso resultou uma falta de políticas mais sistemáticas para a América Latina, o que, no entanto, "deu aos diplomatas [mexicanos] considerável flexibilidade em seus próprios esforços para o aprimoramento das relações do México com a região [latino-americana]". (KIDDLE, 2010, p. 41-42)

A embaixada brasileira de Alfonso Reyes exemplifica muito bem essa relativa autonomia por parte do escritor-embaixador mexicano, especialmente no que diz respeito à questão da solidariedade continental. Embora esse tema já não fosse o prioritário na agenda oficial mexicana nos anos 30, a atuação intelectual de Reyes em favor da aproximação continental cumpriu um papel importante para a consolidação de uma sensibilidade americanista entre parte da intelectualidade brasileira e a publicação de Monterrey ocupou um espaço significativo nesse processo.

Já no primeiro número de seu "correio literário" o escritor-embaixador mexicano endossou a visão de seu país como o grande articulador da solidariedade continental. Isso ocorreu em uma polêmica literária voltada especificamente para a questão da identidade mexicana no continente, por ocasião da publicação de uma antologia da literatura hispanoamericana em francês, pelo escritor franco-argentino Max Daireaux, sem a inclusão do México. Alfonso Reyes dirigiu a Daireaux uma carta aberta - que foi publicada em Monterrey - de conteúdo extremamente crítico, na qual questionava a justificativa apresentada para a exclusão do México da referida antologia. Segundo o escritor franco-argentino, o próprio México - descrito como um país de paradoxos: "turbulento, inquieto e lírico, ao mesmo tempo positivista e visionário, realista e quimérico, elegíaco e cruel" - teria "se separado voluntariamente da família latino-americana", já que possuía uma cultura muito particular, formada pelas "tradições astecas e as tradições espanholas." Alfonso Reyes rebateu essas afirmações de uma forma bastante incisiva, enfatizando o papel cumprido pelo México na articulação da solidariedade continental. Assim foi sua resposta ao argumento de Daireaux:

Não meu amigo, isso não! Você se esquece que a era de intercomunicação americana em que hoje vivemos foi aberta pelas grandes embaixadas espirituais que o México enviou ao sul do continente. [...] O que procuramos fazer, que consigna tínhamos a não ser a de recordar a

${ }^{19}$ Um elemento marcante nessa estratégia foi o empenho da diplomacia mexicana para conquistar a entrada do país na Sociedade das Nações, o que ocorreu em 1931. Consultar a respeito: Herrera León (2009). 
nossos irmãos do Continente a profunda solidariedade que nos une? Você se esquece que toda a juventude americana contempla com interesse e nobre admiração os empenhos do México em suas indagações e sondagens da alma americana. Podemos citar mais de um homem que recebeu no México o batismo continental que merecia, não porque lá tenhamos delegação especial nem prioridade, que não pretendemos, mas simplesmente porque a Ideia Americana se mostra lá em todo seu vigor. [...]. E agora já não vamos complicar ainda mais esse tradicional enigma do México! Já não sabemos onde colocá-lo! Onde está o México, meu amigo, se o mundo só chama de América do Norte aos Estados Unidos e, agora, você nos exclui do Orbe Hispano-Americano? (Monterrey, $\mathrm{n}^{\circ} 1$, junho de 1930, p. 3)

Essa resposta de Reyes foi publicada em "Guardias de la Pluma", uma coluna de Monterrey que contou com uma "explicação" por parte do editor do periódico a seus "amigos" leitores quanto ao caráter essencialmente polêmico que pretendia empregar à palavra "guarda" e à própria coluna. Ao serem (a coluna e seu título) erroneamente associados ao sentido de "guardião" - da cultura, da literatura, etc. -, Reyes explicou que queria lhes conferir um sentido bélico, sendo a "pluma" tomada como "espada"; queria, por meio do emprego de um vocábulo que remetia à ideia de combate, dar à coluna "uma intenção polêmica". Mais do que uma discussão simplesmente cultural/literária, havia indubitavelmente um sentido político nesses debates/combates, como mostra a aludida resposta de Reyes a respeito da identidade latino-americana e o lugar do México no continente. Conforme citamos, o escritor-diplomata mexicano não poupou palavras para defender a atuação de seu próprio país como o centro articulador da aproximação continental e o papel essencial cumprido pela cultura nesse processo.

Mas a argumentação de Reyes sobre a atuação mexicana na promoção de uma "profunda solidariedade" continental - as "grandes embaixadas espirituais" enviadas pelo país à América do Sul e o México como espaço de "batismo continental" de intelectuais latinoamericanos (entre os quais se destaca, no cenário brasileiro, o caso de Ronald de Carvalho) ${ }^{20}$ - remetia muito mais à estratégia diplomática que foi priorizada pelo país nos anos anteriores

\footnotetext{
${ }^{20}$ A própria atuação diplomática de Alfonso Reyes na Argentina e no Brasil é um grande exemplo das "embaixadas espirituais" do México na América do Sul, bem como o envio, mais pontual, de intelectuais para representar o país hispânico da América do Norte no sul do continente, através das chamadas "missões culturais". No caso do Brasil, durante os anos 20, destacaram-se principalmente as presenças dos filósofos Antonio Caso e José Vasconcelos; este, em 1922, como secretário de Educação Pública, e aquele, em 1921, como reitor da Universidade Nacional do México. Além do envio de intelectuais mexicanos à América do Sul, as "missões culturais" do governo mexicano também envolveram a visita de intelectuais sul-americanos ao México. No que diz respeito ao Brasil, um caso extremamente significativo foi o do poeta Ronald de Carvalho, cuja viagem ao México - como acompanhante do jurista Rodrigo Otávio, de quem era auxiliar de gabinete no Itamaraty - marcou profundamente seu itinerário poético. Sobre a importância dessas "missões culturais" para a propaganda externa do México pós-revolucionário, incluindo o caso de Ronald de Carvalho (DIAS, 2015).
} 
do que no período em que escrevia. Aliás, é significativo notar que Reyes identificou o momento de sua escrita, inícios dos anos 30, como uma época em que a "intercomunicação americana" já seria uma realidade e não deixou de ressaltar que essa era, em grande medida, fruto da ação diplomático-cultural realizada por seu próprio país.

Certamente Reyes tinha clareza da limitação que o argumento de que se vivia uma era de intercomunicação continental comportava especialmente em relação ao caso do Brasil, onde, historicamente, o latino-americanismo não tinha desenvolvido raízes mais profundas. Nosso argumento em relação ao tema é o de que a publicação de Monterrey por Alfonso Reyes no Brasil, nos anos 30, cumpriu um papel importante no sentido de dar continuidade ao projeto latino-americanista fomentado pelo México revolucionário nas décadas anteriores.

\section{Monterrey, o latino-americanismo de Alfonso Reyes e os escritores brasileiros}

Um fato que ilustra bem o sucesso, ao menos relativo, da promoção do ideário latinoamericanista de Reyes no Brasil - e também o uso de seu "correio literário" como instrumento de difusão do mesmo - é a formulação do conceito de "homem cordial" pelo escritor Ribeiro Couto, precisamente em uma carta enviada a Alfonso Reyes, em 1931, e que foi parcialmente reproduzida em Monterrey. As correspondências trocadas entre ambos indicam que essa amizade intelectual foi iniciada por intermédio do poeta Manuel Bandeira. Este, sabendo da admiração que Ribeiro Couto nutria pelo trabalho literário de Reyes, teria lhe dado o primeiro número de Monterrey, o que teria encorajado o brasileiro a escrever ao mexicano de Paris, onde atuava como representante diplomático brasileiro. ${ }^{21}$

Em sua primeira carta a Alfonso Reyes, datada de 1931, Ribeiro Couto comentou elogiosamente a argumentação do escritor-embaixador mexicano, publicada no primeiro número de seu periódico, a respeito da exclusão do México da antologia literária publicada na França, à qual fizemos referência anteriormente. $O$ brasileiro se manifestou em relação ao tema da seguinte forma: "não se pode compreender [...] que o México tenha sido excluído de um manual de literatura hispano-americana, principalmente quando a América do Norte é uma expressão de exclusivo sentido anglicano." A essa consideração, agregou uma reflexão mais ampla sobre a diversidade cultural que, em sua concepção, caracterizava o continente americano:

\footnotetext{
${ }^{21}$ De Alfonso Reyes Para: Ribeiro Couto. Carta a Alfonso Reyes, 07/03/1931. Essa correspondência faz parte do Acervo da Capilla Alfonsina (ACA). (COUTO, 1931).
} 
Não lhe parece que haverá sempre uma oposição fundamental entre os anglo-saxões da América [...] e os latinos dessa mesma América [...]? [...] Não sei... Uma coisa me ronca aqui dentro que nunca poderei amar os Estados Unidos da América do Norte. Será por causa de um pouco de sangue negro que tenho nas veias? Não sei, não sei, nem me importa. A realidade é que vejo o conflito preexistir, claro, insofismável, em nossas Américas. De resto, um povo que isolou no ódio e no desprezo 12 ou 13 milhões de negros não tem autoridade para pretender simpatizar com o resto da América... Pois, nesse resto da América, algumas nações, principalmente o Brasil, foram enriquecidas pelo sangue negro e índio, e outras, principalmente o Peru e o México, foram enriquecidas pelo sangue índio... Os Estados Unidos da América também tinham índios, mas os extinguiram a bala, e os mestiços que restam são tão desprezados, ou quase, como os negros (COUTO, 1931).

Dessas palavras podemos depreender que o principal traço característico da América Latina, na avaliação de Ribeiro Couto, seria a capacidade de assimilar positivamente a mestiçagem étnico-cultural, o que diferenciaria a "nossa América" da América "anglicana", ou seja, anglo-saxônica. O brasileiro foi ainda mais longe em sua argumentação e chegou a defender a ideia de que essa América mestiça seria a fonte de uma nova forma de ser e sentir, à qual chegou a atribuir o sentido de uma nova "civilização". O que mais chama a atenção, no entanto, é o fato de Ribeiro Couto atribuir a base de suas reflexões ao americanismo de Alfonso Reyes. Foi nesses termos que o brasileiro formulou sua argumentação sobre o "homem cordial" como um "produto" latino-americano:

O seu americanismo, Alfonso Reyes, é o mais inteligente que conheço. Repele a ideia de um indianismo, de um purismo étnico local, de um primitivismo, mas chama a contribuição das raças primitivas ao homem ibérico; de modo que o homem ibérico puro seria um erro (classicismo) tão grande como o primitivismo puro [...]. É da fusão do homem ibérico com a terra nova e as raças primitivas que deve sair o "sentimento americano" (latino), a raça nova[,] produto de uma cultura e de uma intuição virgem, o Homem Cordial. Nossa América, a meu ver, está dando ao mundo isto: o Homem Cordial. [...] Esses [os Homens Cordiais] se distinguem do resto da humanidade por duas características essencialmente americanas: o espírito hospitaleiro e a tendência à 
credulidade. Numa palavra, o Homem cordial. (Atitude oposta ao europeu: a suspicácia e o egoísmo do lar fechado a quem passa). (Como é bom, nos pueblos e aldeiolas [sic] da nossa América, no seu México como no meu Brasil, mandar entrar o caixeiro-viajante francês que vende peças de linho, ou o engenheiro alemão que está estudando geologia local, e convidá-lo para almoçar! A gente grita logo lá para dentro: - Ô Fulana, manda matar uma galinha!) [...] O fato, porém, é que se não somos latinos, nós oriundos de aventura peninsular celtibérica em terras americanas [...], se não somos latinos, somos qualquer coisa de muito diferente pelo espírito e pelo senso da vida cotidiana. Somos povos que gostam de conversar, de fumar parados, de ouvir viola, de cantar modinhas, de amar com pudor, de convidar o estrangeiro a entrar para tomar café [...]. Essa atitude de disponibilidade sentimental é toda nossa, é ibero-americana. Observável nos nadas, nas pequeninas insignificâncias da vida de todos os dias, ela toma vulto aos olhos do crítico, pois são índices dessa Civilização Cordial que eu considero a contribuição da América Latina ao mundo (COUTO, 1931).

No fragmento da carta publicado em Monterrey, Reyes excluiu a vinculação que Ribeiro Couto estabeleceu entre o seu próprio americanismo e o do escritor-embaixador mexicano; nas páginas do periódico, "o seu americanismo", ou seja, o de Reyes, foi mudado para "o verdadeiro americanismo". (Monterrey, $\mathrm{n}^{\circ}$ 8, março de 1932, p. 3. Grifo nosso ) A apropriação mais conhecida da noção de "homem cordial" foi feita por Sérgio Buarque de Holanda, em um ensaio intitulado precisamente "O homem cordial", publicado originalmente em Raízes do Brasil, de 1936. No texto, o historiador remete o leitor à "feliz expressão" de Ribeiro Couto e informa ter tomado conhecimento da mesma precisamente através de Monterrey - o que, aliás, aponta para a inserção intelectual do periódico de Reyes. Entretanto, no referido ensaio, cujo foco era o caráter nacional brasileiro, Sérgio Buarque identificou a "cordialidade" como "a contribuição brasileira para a civilização", ${ }^{22}$ afastando da noção o sentido latino-americano que foi dado originalmente por Ribeiro Couto, mantido e reiterado no fragmento de sua carta

\footnotetext{
${ }^{22}$ Cabe aqui ressaltar a leitura realizada por Sérgio Buarque a respeito da noção de homem cordial de Ribeiro Couto. Como é sabido, para o historiador brasileiro a noção de cordialidade não se relaciona ao atributo positivo da bondade, nem necessariamente à ideia de concórdia, mas remete ao "sentido exato e estritamente etimológico" da palavra, relacionado àquilo que "nasce do coração", ou seja, que provém da esfera do íntimo, do privado. O autor contrapõe "cordialidade" à "civilidade", naquilo que esta última possui de "coercitivo", destacando que, diferentemente desta, a "forma ordinária de convívio social" no "homem cordial" expressa espontaneidade, portanto, o contrário da noção de "polidez", que remete à lógica da formalidade, à convenção social. Na visão do historiador, a cordialidade característica do caráter brasileiro expressaria a permanência "ativa e fecunda" dos ancestrais "padrões de convívio humano, informados no meio rural e patriarcal", relacionados ao familiar e privado. Para Sérgio Buarque, essa noção estritamente etimológica da cordialidade "já esta[va] implícit[a] no texto" de Ribeiro Couto e mesmo assim acabou sendo erroneamente associada - por outros autores, entre os quais cita Cassiano Ricardo - à aludida noção de bondade. Por isso, o historiador brasileiro incluiu uma longa nota explicativa do termo em seu ensaio. (HOLANDA, 2012, p. 52-53, 101-102).
} 
que foi reproduzido em Monterrey acompanhado do título, dado por Reyes: "O Homem Cordial, produto americano." (Idem, p. 3.)

Na reflexão original de Ribeiro Couto, a busca da "autêntica" identidade cultural latinoamericana emergia frente ao reconhecimento de uma diferença "insofismável" em relação às realidades europeia e estadunidense. Tratava-se de uma reflexão identitária que conseguia ultrapassar a busca pelas especificidades nacionais, tão comuns na época, para plasmar-se em uma identificação de caráter latino-americano. O uso estratégico que Alfonso Reyes empregou a essas e outras reflexões identitárias de caráter continental formuladas por brasileiros para a promoção do seu latino-americanismo através de Monterrey é algo que se torna evidente quando observamos que, na mesma página do periódico em que aparece o fragmento da carta de Ribeiro Couto, o escritor-embaixador mexicano também inseriu um trecho de uma outra carta, que havia recebido do escritor Prudente de Moraes Neto (MORAES NETO, 28/04/1931, ACA), e que também versava sobre o tema da identidade continental. Reyes submeteu ao título "Espaço e tempo na alma americana" as seguintes considerações do brasileiro sobre o que considerava ser "uma fusão entre os dois elementos que a todos nós, da América, mais ou menos nos disputam":

\begin{abstract}
Se o crítico e humanista não pode negar a procedência europeia, o poeta é atraído pelo espetáculo da terra e do meio-social [sic], a cujo serviço, aliás, sempre coloca a sua cultura. [...] As nossas ligações com a Europa se acentuam no plano temporal, enquanto que com a América elas [se] processam no espaço. História e geografia. Tradição e realidade. [...] E somos feitos de tal modo, que para muitos ainda hoje é [a] Europa a verdadeira realidade. [...] A maior parte dos que entre nós se dedicam a questões intelectuais ou artísticas comportam-se diante da América como simples viajantes. Daí a criação de uma arte e de uma literatura exóticas, embora nascidas aqui [...]. (MORAES NETO, apud Monterrey, $\mathbf{n}^{\circ}$ 8, março de 1932, p. 3)
\end{abstract}

Ao reproduzir em seu periódico dois grandes e densos fragmentos assinados por importantes intelectuais brasileiros, o escritor-embaixador mexicano podia expressar, indiretamente, o sucesso de sua própria atuação americanista no Brasil. É, de fato, perceptível a "sombra" de Alfonso Reyes no americanismo esboçado pelos escritores brasileiros. Em ambos se destaca como essencial a busca de uma identidade latino-americana específica, da particularidade cultural - e mesmo sociológica, no caso do "homem cordial" - que caracterizaria a região; mas essa busca não se traduzia em uma negação da cultural ocidental ou em qualquer tipo de proposta de caráter indo-americano que significasse renegar a 
"tradição" europeia. Tratava-se do mesmo americanismo já então explicitado por Reyes em seu famoso ensaio Discurso por Virgilio, um dos escritos mais importantes para a compreensão da visão de Reyes sobre a identidade cultural continental e que foi escrito no Rio, em 1930, tendo sido publicado no México no ano seguinte (originalmente na revista Contemporáneos) e distribuído pelo mexicano aos seus "amigos" cariocas.

No ensaio, Reyes apresentou uma visão da América de colonização ibérica como parte da "civilização latina", a qual deveria ser tomada como "um conceito largo e elástico" que excedesse o espaço europeu e o período histórico da Antiguidade e cujo cerne deveria ser colocado exatamente em seu caráter de abertura para a "intercomunicação" cultural. Nesse sentido, criticou uma certa perspectiva da "hora americana" - alcunha do movimento reformista universitário iniciado em Córdoba, na Argentina, em 1918, que expressava seu caráter continental -, que preconizava a decadência europeia em contraste com a visão de uma América "florescente sob uma chuva de virtudes", em suas irônicas palavras. Para o escritor-emabixador mexicano, a defesa da identidade latino-americana não podia equivaler a voltar as costas para a Europa e para as conquistas civilizacionais dela decorrentes. Ao contrário, entendia que a especificidade latino-americana encontrava-se não na defesa de particularidades autóctones, mas precisamente na capacidade de "acolher todas as conquistas [humanas], procurando com todas elas uma elaboração sintética." Tal virtude, afirmava o mexicano, derivava exatamente da "alma latina" que animava a cultura do continente americano. (REYES, 2009 [1930], p. 111; 122; 124-5)

Essa compreensão da identidade continental sustentada por Reyes, na realidade, caminhava na contramão da posição oficial mexicana empunhada nos anos 30, quando a ênfase era cada vez mais colocada no particularismo nacional e a proposta de que o México revolucionário servisse de modelo para o continente ganhava uma conotação marcadamente nacionalista e indigenista (PÉREZ MONTFORT, 1994) Foi justamente visando combater a identificação nacional sustentada na "mexicanidade" que o escritor-diplomata retomou a figura do poeta clássico, Virgílio, como o ponto de partida para a defesa de uma identidade latino-americana afastada de todo localismo e inclinada à intercomunicação universal.

Portanto, mesmo dissonante da posição oficial mexicana por sua crítica ao nacionalismo e à perspectiva indo-americana, o latino-americanismo de Alfonso Reyes foi difundido, através do seu Monterrey, de uma maneira bastante autônoma, apesar de seu papel como representante oficial do Estado mexicano.

\section{Considerações Finais}


Como procuramos mostrar ao longo do texto, uma abordagem política do periódico Monterrey. Correo literario de Alfonso Reyes permite explorar uma dimensão significativa desta produção cultural que, apesar do inegável personalismo que a marcou, não deixou de estar intimamente relacionada à diplomacia cultural de cunho latino-americanista e anti panamericanista esgrimida pelo México pós-revolucionário no cenário continental.

A análise do "correio literário" privilegiando os elementos políticos que o perpassaram revelou que, apesar do alinhamento do escritor-embaixador à política continental mexicana, manifesto em seu periódico, a leitura do mesmo também permite identificar certa discordância de Reyes frente aos rumos mais particularistas - o sentido indo-americano e a valorização da "mexicanidade" - tomados pela política oficial mexicana nos anos 30. Nesse contexto, como argumentamos, o discurso latino-americanista de Monterrey vincula-se muito mais à política externa seguida pelo México nos anos anteriores, quando o fomento da solidariedade continental ocupou a centralidade da diplomacia do país.

Assim, o "correio literário" de Reyes cumpriu um papel de propaganda internacional do México revolucionário - principalmente na coluna "Noticia Mexicana", mas também em outros espaços do periódico -, inclusive projetando internacionalmente a imagem do país como o grande articulador da identidade latino-americana. Embora o latino-americanismo de Alfonso Reyes em alguns momentos tenha destoado da política oficial da Secretaria de Relações Exteriores do México, sua significativa atuação intelectual no cenário cultural carioca - dentro da qual se destaca a publicação de Monterrey - permitiu que a sua própria perspectiva sobre a identidade continental gerasse frutos tão significativos quanto a emergência de uma sensibilidade intelectual mais inclinada à inserção do Brasil numa identidade continental. Isso fica evidente nas citadas reflexões latino-americanistas desenvolvidas por escritores brasileiros e publicadas no "correio literário" do escritorembaixador mexicano.

\section{Referências}

AGUILAR, Marcos Daniel. La estrategia alfonsina en Brasil. In: REIS, Lívia (Org.). Uma suíte carioca: Alfonso Reyes e o Brasil. Rio de Janeiro: 7 Letras, 2013.

ALTAMIRANO, Carlos. Introducción general. In: Historia de los intelectuales en América Latina. I. La ciudad letrada, de la conquista al modernismo. Buenos Aires: Katz, 2008, p. p. 9-27 
BAGGIO, Kátia Gerab. A "outra" América: a América Latina na visão dos intelectuais brasileiros das primeiras décadas republicanas. 1998. 224 f. Tese (Doutorado em História Social) Departamento de História, Universidade de São Paulo, São Paulo.

BUENO, Clodoaldo. A política externa da Primeira República: os anos de apogeu - de 1902 a 1918, Rio de Janeiro: Paz e Terra, 2003.

CARBALLO, Emmanuel et al. Escritores en la diplomacia mexicana. México: Secretaría de Relaciones Exteriores, 1998.

CARVALHO, Ronald. "Cobardía” de Amado Nervo contra os tradutores brasileiros. Monterrey, n. 5 , jul. 1931.

CASTAÑón, Adolfo. Trazos para una bibliografia comentada de Alfonso Reyes. México: UNAM, 2005.

COUTO, Ribeiro. Origem do conceito do homem cordial. Carta a Alfonso Reyes, 7 mar. 1931. Disponível em: <https://www.correioims.com.br/carta/origem-do-conceito-de-homemcordial/>. Acesso em: 5 jun. 2014.

DIAS, Natally Vieira. A Revolução Mexicana nos debates político-intelectuais brasileiros: projeções, leituras e apropriações (1910-1941). 2015. 302 f. Tese (Doutorado) - Universidade Federal de Minas Gerais, Belo Horizonte.

DIAS, Natally Vieira. Diplomacia e atuação intelectual: Alfonso Reyes e a Embaixada mexicana no Brasil (1930-1936). Temporalidades, Belo Horizonte, v. 5, n. 1, p. 97-110, jan./abr. 2013.

DÍAZ ARCINIEGA, Víctor (Comp.). Voces para un retrato: ensayos sobre Alfonso Reyes. México: Universidad Autónoma Metropolitana (Azcapotzalco); Fondo de Cultura Económica, 1990.

DÍAZ ARCINIEGA, Víctor. Prólogo: El organizador de la esperanza. In: REYES, Alfonso. Misión diplomática. México: FCE, 2001. Tomo I, p. 9-99.

DUROSELLE, Jean-Baptiste. Todo imperio perecerá: teoría sobre las relaciones internacionales. México, Fondo de Cultura Económica, 1998.

ENRÍQUEZ PEREA, Alberto. Alfonso Reyes en los albores del Estado Nuevo brasileño (1930-1936). México: El Colegio Nacional, 2009.

GARCIADIEGO, Javier. Alfonso Reyes: cosmopolitismo diplomático e universalismo literario. In: CARBALLO, Emmanuel et al. Escritores en la diplomacia mexicana. México: Secretaría de Relaciones Exteriores, 1998.v. 1, p. 191-222. 
GRANADOS, Aimer. Alfonso Reyes en Sur América: diplomacia y campo intelectual en América Latina, 1927-1939. Historia y Espacio, Cali, Colômbia, n. 38, p. 6-22, 2012 ${ }^{\text {a }}$.

GRANADOS, Aimer. Monterrey. Correo Literario de Alfonso Reyes. Campo literario y red intelectual en América Latina. In: GRANADOS, Aimer (Coord.). Las revistas en la historia intelectual de América Latina: redes, política, sociedad y cultura. México: Universidad Autónoma Metropolitana; Juan Pablos Editor, 2012b. p. 85-100.

HERRERA LEÓN, Fabián. La política mexicana en la Sociedad de Naciones ante la Guerra del Chaco y el conflito de Leticia, 1923-1935. México: Secretaría de Relaciones Exteriores, 2009.

HOLANDA, Sérgio Buarque de. O homem cordial [1936]. São Paulo Companhia das Letras, 2012.

KIDDLE, Amelia. La Politica del Buen Amigo: Mexican-Latin American relations during the presidency of Lázaro Cárdenas, 1934-1940. 2010. Dissertation (Doctor of Philosophy) - University of Arizona, Arizona, 2010. Disponível em: <http://arizona.openrepository.com/arizona/bitstream/10150/193655/1/azu_etd_11015_sip1 _m.pdf $>$. Acesso em: 20 ago. 2014.

LA CUEVA, Alicia Azuela de. Alicia. Arte y poder. México: Fondo de Cultura Económica; El Colegio de Michoacán, 2003.

LA CUEVA, Alicia Azuela de. Vanguardismo pictorio y vanguardia política en la construcción de Estado nacional revolucionário mexicano. In: ALTAMIRANO, Carlos (Ed.). Historia de los intelectuales en América Latina II: los avatares de la "ciudad letrada" en el siglo XX. Buenos Aires: Katz, 2010. p. 469-489.

LA CUEVA, Alicia Azuela de; PALACIOS, Guillermo (Coord.). La mirada mirada: transculturalidad e imaginarios del México revolucionario (1910-1945). México: COLMEX; UNAM, 2009.

MILZA, Pierre. Política interna e política externa. In: RÉMOND, René (Org.). Por uma história política. Rio de Janeiro: FGV, 2003. p. 365-399.

Monterrey. Correo literario de Alfonso Reyes. “Guardias de la Pluma” nº 1, junho de 1930, p. 3. “Noticia Mexicana”, n 1, junho de 1930, p. 4-5. “Noticia Mexicana”, nº 5, junho de 1931, p. 5-6. ."El hombre cordial: producto americano", no 8, março de 1932, p. 3.

MORAES NETO, Prudente de. Cartas a Alfonso Reyes, 1931. Acervo da Capilla Alfonsina. 
PACHECO, Jose Emilio et al. Monterrey. Correo literario de Alfonso Reyes (1930-1937). Monterrey: Fondo Editorial Nuevo León, 2008.

PALACIOS, Guillermo. Intimidades, conflitos e reconciliações. México e Brasil, 1822-1993. São Paulo: EDUSP 2008.

PÉREZ MONTFORT, Ricardo. Indigenismo, hispanismo y panamericanismo en la cultura popular mexicana de 1920 a 1940. In: BLANCARTE, Roberto. Cultura e identidad nacional. México: FCE, 1994. p. 343-83.

PRADO, Maria Ligia. O Brasil e a distante América do Sul. Revista de História, São Paulo, n. 145, p. 128-149, 2001.

REIS, Lívia. Monterrey no Rio de Janeiro: Alfonso Reyes e o Brasil. In: HELENA, Lúcia (Org.). Literatura, intelectuais e crise da cultura. Rio de Janeiro: Contracapa, 2007.

REMOND, René (Org.). Por uma história política. Rio de Janeiro: FGV, 2003.

REYES, Alfonso. Discurso por Virgilio [1930]. In: REYES, Alfonso. La experiencia literaria y otros ensayos. (Selección y prólogo de Jordi García). Guadalajara-México: Fundación Banco Santander, 2009.

REYES, Alfonso. El servicio diplomático mexicano [1933]. In: REYES, Alfonso. Misión diplomática. México: FCE, 2001. Tomo I, p. 124-165.

REYES, Alfonso. “Propósito". Monterrey. Correo literario de Alfonso Reyes. nº 1, 1930, p. 2.

RIBEIRO, Edgar Telles. Diplomacia cultural: seu papel na política exterior brasileira. Brasília: Fundação Alexandre Gusmão, 2011.

YANKELEVICH, Pablo. En la retaguardia de la Revolución Mexicana: Propaganda y propagandistas mexicanos en América Latina, 1914-1920. Boletín Americanista, Barcelona, $\mathrm{n}$. 49, 1999. Disponível em: <http://dialnet.unirioja.es/servlet/listaarticulos? tipoDeBusqueda $=$ ANUALIDAD\&revistaDeBusqueda $=5730$ \&claveDeBusqueda $=1999>$. Acesso em: 5 jun. 2014.

YANKELEVICH, Pablo. Miradas australes. Propaganda, cabildeo y proyección de la Revolución Mexicana em el Río de la Plata, 1910-1930. México: Instituto Nacional de Estudios Históricos de la Revolución Mexicana, Secretaría de Relaciones Exteriores, 1997.

ZAÏTZEFF, Serge I. (compilación y notas). Con leal franqueza: correspondencia entre Alfonso Reyes y Genaro Estrada. Tomo III (1930-1937). México: El Colegio Nacional, 1993.

Recebido em: 29/10/2017 - Aprovado em 27/04/2018 